\title{
Escala predictiva diagnóstica de infección urinaria en neonatos febriles sin foco aparente
}

\author{
LUIS ALFONSO MENDOZA T. ${ }^{1}$, CLAUDIA L. CANO B. ${ }^{2}$, MIGUEL ÁNGEL OSORIO R. ${ }^{3}$, \\ MARTHA D. ARIAS G. ${ }^{4}$, LAURA I. MENDOZA T. \\ 1. Unidad Neonatal, Fundación Hospital San José de Buga. Unidad Central del Valle, Tuluá, Colombia. \\ 2. Fundación Universitaria San Martín, Sede Cali, Colombia. \\ 3. Unidad Neonatal, Hospital Universitario del Valle. Universidad del Valle, Colombia. \\ 4. Departamento de Pediatría, Fundación Hospital San José de Buga, Colombia. \\ 5. Unidad Central del Valle, Tuluá, Colombia.
}

\section{ABSTRACT \\ A diagnostic predictive scale for urinary tract infection in febrile infants without an apparent focus}

Introduction: Urinary tract infection (UTI) is the most frequent bacterial infection in infants with nonspecific clinical manifestations. Objective: To validate a predictive scale for UTI in febrile infants without apparent source and hospitalized in a neonatal unit. Patients and Method: A nested case-control study was conducted on 158 infants with febrile UTI, culture-confirmed, and on 346 febrile infants without apparent focus in whom UTI was ruled out, and also, hospitalized in a neonatal unit. The analysis was performed using Stata ${ }^{\circledR}$ 11. Associations were determined using odds ratio (OR) with $95 \%$ confidence interval. To find the predictive scale, multivariate analysis was performed using logistic regression and establishing major and minor criteria according to regression coefficient. Yield was calculated by sensitivity, specificity and area under ROC curve. The new predictive scale was validated by 108 new febrile neonates. Results: The major criteria to predict UTI were abnormal urinalysis and Gram positive cells without centrifugation, and among the minor criteria, male, age at time of fever, previous neonatal hospitalization, abnormal temperature $\left(38.5^{\circ} \mathrm{C}\right.$ or more, persistent fever, hypothermia) and $1.7 \mathrm{mg} / \mathrm{dL} \mathrm{C}$ reactive protein or higher, resulting positive with the presence of one mayor or three minor criteria. It showed good performance with 100\% sensitivity (CI 95\%:98.3-100\%), 92.3\% specificity (CI 95\%: 85.8-98.9\%) and 0.962 area under ROC (95\% CI: 0.932-0.991) when validated on 108 new febrile neonates without focus. Conclusions: The new predictive scale allows predicting UTI with good yield in infants with fever without an identified source.

(Key words: Fever of unknown origin; neonate; urinary tract infection; predictive scale).

Rev Chil Pediatr 2014; 85 (1): 52-63

Recibido el 26 de abril de 2013, devuelto para corregir el 1 de julio de 2013, segunda versión 28 de julio de 2013, tercera versión 14 de octubre de 2013, aceptado para publicación el 30 de noviembre de 2013.

Este trabajo cumple con los requisitos sobre consentimiento /asentimiento informado, comité de ética, financiamiento, estudios animales y sobre la ausencia de conflictos de intereses según corresponda.

Correspondencia a:

Luis Alfonso Mendoza Tascón

E-mail: lamendozat@gmail.com 


\section{RESUMEN}

Introducción: La infección de tracto urinario (ITU) es la infección bacteriana más frecuente en neonatos, con manifestaciones clínicas inespecíficas. Objetivo: Validar una Escala Predictiva de ITU en neonatos febriles sin foco aparente, hospitalizados en una unidad neonatal. Pacientes y Método: Estudio caso control anidado en una cohorte, realizado en 158 neonatos febriles con ITU, confirmada por cultivo y 346 neonatos febriles sin foco aparente, en quienes se descartó ITU, hospitalizados en una unidad neonatal. El análisis se realizó con Stata ${ }^{\circledR}$ 11. Las asociaciones se determinaron mediante odds ratio (OR), con su intervalo de confianza de $95 \%$. Para hallar la Escala Predictiva, se realizó análisis multivariado mediante regresión logística, estableciendo criterios mayores y menores de acuerdo al coeficiente de regresión, mientras el rendimiento se determinó con sensibilidad, especificidad y área bajo ROC. La nueva Escala Predictiva se validó con 108 neonatos febriles nuevos. Resultados: Los criterios mayores para la predicción diagnóstica de ITU fueron uroanálisis alterado y Gram de orina sin centrifugar positivo, y los criterios menores, sexo masculino, edad al momento de la fiebre mayor a 7 días, hospitalización neonatal previa, alteración de la temperatura $\left(38,5^{\circ} \mathrm{C}\right.$ o más, fiebre persistente, hipotermia) y proteína $\mathrm{C}$ reactiva $1,7 \mathrm{mg} / \mathrm{dL}$ o mayor, siendo positiva con un criterio mayor o tres menores. Esta mostró buen rendimiento con sensibilidad 100\% (IC 95\%: 98,3-100\%), especificidad 92,3\% (IC 95\%: 85,8-98,9\%) y área bajo ROC 0,962 (IC 95\%: 0,932-0,991) cuando se validó en 108 nuevos neonatos febriles sin foco. Conclusiones: La nueva Escala Predictiva permite con buen rendimiento predecir una ITU en neonatos con fiebre sin foco aparente.

(Palabras clave: Fiebre sin foco aparente; neonato; infección de vías urinarias; Escala Predictiva).

Rev Chil Pediatr 2014; 85 (1): 52-63

\section{Abreviaturas}

\begin{tabular}{|ll|}
\hline ITU: & Infección de vías urinarias \\
\hline OR: & Odds ratio \\
RVU: & Reflujo vesicoureteral \\
UCIN: & Unidad de cuidados intensivos neonatales \\
ROC: & $\begin{array}{l}\text { Receiver Operating Characteristic, o Característica } \\
\text { Operativa del Receptor }\end{array}$ \\
ORc: & Odds ratio crudo \\
ORa: & Odds ratio ajustado \\
DE: & Desviasción estándar \\
RI: & Rango intercuartil \\
\hline
\end{tabular}

\section{Introducción}

La fiebre es una manifestación clínica importante de infección en el período neonatal y constituye una causa frecuente de consulta $(13,6 \%)$ y hospitalización $(31,3 \%)$ en unidades neonatales ${ }^{1}$. Esta tiene muchas causas, entre las cuales están las infecciones bacterianas ${ }^{2}$. Entre las infecciosas bacterianas del período neonatal, la más frecuente es Infección del Tracto Urinario (ITU) $(51,2 \%)$, superando a la sepsis $(11,9 \%)$, neumonía $(3,3 \%)$, meningitis $(5,4 \%)$ y enfermedad diarreica aguda $(2,2 \%)^{3}$.
La ITU incluye una variedad de trastornos que afectan el aparato urinario en toda su extensión, aun desde infecciones asintomáticas, hasta condiciones que amenazan la vida, como la pielonefritis aguda ${ }^{4-6}$. Entre los años 19501963 informan una tasa de incidencia de ITU en neonatos de 0,7 por 1.000 nacidos vivos (nv) por año, para 1964 esta tasa se duplicó a 1,5 por 1.000 nv por año y entre 1965-1967 fue tres veces mayor, 4,9 por $1.000 \mathrm{nv}$ por año ${ }^{7}$. Actualmente, la incidencia de la ITU se estima en $0,5-1 \%$ para recién nacidos a términos y $3-5 \%$ en prematuros ${ }^{8}$. La proporción de recurrencia y de complicaciones es de alrededor $12-30 \%$, con un riesgo mayor en lactantes menores de 6 meses y aquellos con reflujo vesicoureteral (RVU), siendo ésta la anomalía del tracto urinario más frecuente $(25-50 \%)$ en el período neonatal ${ }^{9-11}$.

Las manifestaciones clínicas de la ITU en el neonato son inespecíficas y tanto el diagnóstico, como su exclusión representan un reto en la edad neonatal ${ }^{12}$. Los objetivos de este estudio fueron evaluar parámetros clínicos y de laboratorio predictores de ITU en neonatos febriles sin foco aparente y validar una Escala Predictiva. 


\section{Pacientes y Método}

\section{Diseño y población del estudio}

Estudio caso-control anidado en una cohorte de neonatos que ingresaron por fiebre sin foco aparente a la Unidad de Cuidados Intensivos Neonatales (UCIN) de la Fundación Hospital San José de Buga, Colombia, entre los años 2001 y 2012. Se incluyeron neonatos de cualquier edad gestacional, sexo y peso al nacer, quienes tuvieran temperatura rectal de $38^{\circ} \mathrm{C}$ o más o axilar de $37,6^{\circ} \mathrm{C}$ o más al momento del ingreso o durante las primeras 24 $\mathrm{h}$ de observación y que al examen físico no se encontrara evidencia de foco infeccioso, cuya edad estuviera entre 0 a 30 días para los neonatos de término o menor e igual a 44 semanas de edad gestacional corregida para los neonatos menores de 37 semanas al nacer. Se excluyeron aquellos neonatos con sospecha de infección asociada a la atención en salud, reingreso por fiebre en un período 7 días o menos después de un egreso hospitalario, con inmunodeficiencias conocidas, malformaciones congénitas mayores (anencefalia, hidrocefalia congénita, espina bífida, cardiopatías congénitas, atresia de esófago o de intestino, hipoplasia pulmonar, hernia diafragmática, ambigüedad sexual, síndromes polimalformativos), así como neonatos con trisomías, malformaciones anorectales y defectos de pared abdominal, neonatos con otros tipos de infecciones bacterianas graves como sepsis, neumonía, meningitis y neonatos remitidos de otras instituciones que hubiesen recibido antibioticoterapia.

Se consideró como caso a todo neonato febril que tuviera un urocultivo positivo tomado por punción suprapúbica con cualquier número de unidades formadoras de colonias por $\mathrm{mL}$ (UFC/mL) o tomado por sondaje vesical con más de $10.000 \mathrm{UFC} / \mathrm{mL}$. Se consideró como control a todo neonato febril a quien se le haya descartado una infección bacteriana grave, con urocultivo negativo (infección de vías urinarias, sepsis, meningitis, neumonía, enterocolitis necrotizante, infección de piel y tejidos blandos).

Mediante el programa Epidat 3.1 se calculó el tamaño de muestra en 158 casos y 316 controles para un OR de 1,9, con un poder estadístico de $80 \%$, un nivel de confianza de $95 \%$. Para la selección de los casos se incluyeron en el estudio todos los neonatos con ITU del período de estudio que cumplieran con los criterios de inclusión y no tuvieran criterios de exclusión. Los controles se seleccionaron mediante un muestreo aleatorio sistemático desde una base de datos donde se registran todos los neonatos que ingresan a la UCIN con fiebre sin foco aparente. Para la validación se consideró en 108 neonatos febriles sin foco aparente, considerando que la escala tuviese una sensibilidad de $95 \%$ y especificidad de $80 \%$, con una prevalencia de la ITU de $20 \%$, un error absoluto asociado a la estimación de 9,5\%. Para esta validación, se incluyeron de manera prospectiva y consecutiva a todos los que cumplieran con los criterios de inclusión y no tuviesen criterios de exclusión.

Las variables independientes incluyeron edad gestacional al nacer (en semanas), edad cronológica al ingreso (en días), género (masculino o femenino), peso al nacer (en gramos), vía de nacimiento (vaginal o cesárea), factores de riesgo para infecciones bacterianas (maternos, gestacionales, perinatales, neonatales y ambientales), manifestaciones clínicas, hallazgos de laboratorio y cultivos de orina, sangre, líquido cefalorraquídeo u otro líquido estéril si era necesario. La variable dependiente fue ITU confirmada (urocultivo positivo) o descartada (urocultivo negativo).

La información para el desarrollo de la escala se tomó de una base de datos cuyos registros son obtenidos a partir del interrogatorio de la madre, de la evaluación del neonato y de los datos de laboratorio directamente extraídos de los informes. Esta información corresponde a la misma que se registra en la historia clínica institucional para cada neonato. Las historias clínicas materna y neonatal fueron una fuente de información secundaria. La información para la validación de la escala se tomó de manera prospectiva a partir del interrogatorio de la madre, de la evaluación del neonato y de los datos de laboratorio directamente extraídos de los informes. Esta información corresponde a la misma que se registra en la historia clínica institucional para cada neonato. Los datos son recogidos por los pediatras de la UCIN, de ma- 
nera estandarizada, siendo personal experto y entrenado. Los datos de la investigación fueron consignados en un formato en papel diseñado para efectos del estudio. La UCIN cuenta con guía clínica para el diagnóstico y tratamiento del neonato febril sin foco aparente, que incluyen los datos clínicos de la historia que deben ser registrados y los estudios de laboratorio, de microbiología y de imágenes que deben realizarse a todos los neonatos que consulten por fiebre sin foco aparente. Los estudios de laboratorio y los de microbiología tienen técnicas específicas de recolección y de transporte al Laboratorio de la Institución, donde también de manera estandarizada son realizados los respectivos análisis de las muestras recolectadas. Estos estudios de laboratorio y microbiología son tomados al momento del ingreso del paciente a la unidad neonatal, previo al inicio de cualquier terapia, incluyendo la antibiótica. Los laboratorios como hemograma, proteína c reactiva, electrolitos (sodio y potasio), glicemia o glucometría y hemocultivo, son recogidos por una enfermera profesional y entrenada, siguiendo protocolos estandarizados. Las muestras para los estudios de orina y líquido cefalorraquídeo son tomados por el pediatra de turno, procedimientos que también están estandarizados. La orina es recogida por punción suprapúbica o en su defecto por sondaje vesical en el $100 \%$ de los neonatos participantes del estudio. A la orina se realiza uroanálisis, Gram y cultivo. Al líquido cefalorraquídeo se le realiza citoquímico, Gram y cultivo. Las muestras para hemocultivo se incubaron en el sistema automatizado BACTEC 9050 (Becton Dickison). La lectura se realizó MicroScan 4 (Dade Berihng). El medio de cultivo empleado fue el del medio automatizado BACTEC 9050. Los urocultivos se incubaron en medio estándar. La identificación se realizó en MicroScan 4 (Dade Berihng). El medio empleado fue agar sangre al 5\% y agar McConkey. El liquido cefalorraquídeo (LCR) se cultivó en medio enriquecido de caldo de Tioglicolato para luego subcultivarlos en agar sangre 5\% y agar chocolate. La identificación se hizo en MicroScan 4 (Dade Berihng). Los gérmenes Gram positivos y Gram negativos se identifican a través de MicroScan 4 (Dade Berihng). La sensibilidad bacteriana se identifica en MicroScan 4 (Dade Berihng) y se confirma con sensidiscos estándares. A los neonatos que se les hiciera diagnóstico de ITU se les realizaba ecografía renal en busca de malformaciones de vías urinarias y renales y de carácter ambulatorio se ordenaba cistouretrografia miccional.

Este estudio fue aprobado por el Comité de Ética de la institución y careció de conflicto de intereses.

\section{Análisis estadístico}

Los datos fueron trasladados desde una base en Microsoft Office Excel 2007 a Stata ${ }^{\circledR}$ 11.0 para su análisis. Las variables continuas se describieron de acuerdo con su distribución con promedios y desviación estándar o medianas y rangos intercuartiles, para comparar diferencias. Se empleó la prueba t-test no pareado o Wilcoxon rank-sum según correspondiera. Las variables categóricas se expresaron en frecuencias y proporciones y fueron comparadas usando la prueba de $\mathrm{Chi}^{2}$ de Pearson. Para cada una de las variables cuantitativas se determinó su mejor punto de corte que predijera la variable de resultado teniendo en cuenta la sensibilidad, especificidad y área bajo la curva ROC. Para determinar la asociación entre cada variable independiente y la variable de resultado, se calculó el OR con su intervalo de confianza del 95\% (IC 95\%). Se consideró un valor de $\mathrm{p}<0,05$ como estadísticamente significativo. Para el análisis multivariado se empleó la regresión logística. Finalmente, teniendo en cuenta los coeficientes de regresión de cada una de las variables, se establecieron criterios mayores y menores, definiendo como criterio mayor aquella(s) variable(s) con un valor de coeficiente de regresión logística de dos o más veces el valor de las variables con menor coeficiente de regresión logística y criterio menor a las que no cumplieran esta condición, a partir de los cuales se creó la Escala Predictiva. Para establecer el punto de corte de la escala, se tuvo en cuenta la mejor sensibilidad, especificidad y área bajo ROC. Igualmente, se determinaron los valores predictivos y razones de verosimilitud. Para la validación se evaluó la capacidad de predicción de ITU mediante sensibilidad, especificidad, valores 
predictivos, razones de verosimilitud y el área bajo ROC con sus correspondientes IC 95\%.

\section{Resultados}

En el presente trabajo se incluyeron para la construcción de la escala 504 neonatos febriles $\sin$ foco aparente, $158(31,3 \%)$ con ITU, $222(44 \%)$ con fiebre sin foco aparente y sin infección bacteriana y $124(24,6 \%)$ con deshidratación hipernatrémica. Hubo 336 varones $(66,9 \%)$, con una relación hombre:mujer de 14,8:1. La mediana de la edad neonatal fue 10 días (RI: 2-19 días), el promedio de edad gestacional al nacer 39 semanas $( \pm 1,9$ semanas $)$ y el peso al nacer $3.202 \mathrm{~g}( \pm 501,8 \mathrm{~g})$.

Los gérmenes aislados en orina fueron Escherichia coli $(122 ; 77,2 \%)$, Enterobacter cloacae (16; 10,1\%), Klebsiella sp (14; 8,9\%), Enterobacter aerógenes, Enterobacter aglomerans y Enterococcus sp (2; 1,3\% cada uno) De estos, 26 bacterias se aislaron simultáneamente en orina y sangre, Escherichia coli (22; $84,6 \%$ ) y Enterobacter cloacae (4; 15,4\%).

El estudio ecográfico renal y de vías urinarias se realizó en los 158 neonatos con ITU, hallándose anormal según los informes del médico radiólogo en 36 casos $(22,8 \%)$, donde las anomalías halladas fueron, hidronefrosis uni y bilateral de diferentes grados (24 casos; $15,2 \%$ ), inflamación renal bilateral ( 5 casos; $3,2 \%$ ) y riñón poliquístico unilateral ( 2 casos; $1,3 \%)$. Se tuvieron informes de 26 cistouretrografías miccionales realizadas, hallándose normales $20(76,9 \%)$ y con reflujo vesicouretral 6 casos $(23,1 \%)$, dos de ellos con doble sistema ureteral $(7,7 \%)$.

Para las variables maternas como edad, educación (años de estudio), paridad, estrato socio-económico, número de visitas en el control prenatal, no se encontraron diferencias estadísticamente significativas entre neonatos con y sin ITU, mientras para la ausencia de seguridad social, hallamos una mayor proporción de madres de neonatos con ITU sin seguridad social en salud $(6,4 \%$ vs $2,6 \% ; \mathrm{p}<0,042)$. Para las variables neonatales hallamos diferencias estadísticamente significativas para sexo, con mayor proporción hombres entre neonatos con
ITU (93,7\% vs 53,7\%, p < 0,001), para edad al momento de la fiebre, la cual fue mayor entre neonatos con ITU (mediana 15 días; RI: 11-23 días vs mediana 3; RI: 2-14 días; $\mathrm{p}<0,001$ ) y para hospitalización neonatal previa, la cual fue mayor en neonatos con ITU $(15,2 \%$ vs $2,9 \% ; \mathrm{p}<0,001)$, no hallando diferencia estadísticamente significativa para edad gestacional al nacer, peso al nacer y vía de nacimiento, (tabla 1).

Entre las manifestaciones clínicas, hallamos que la alteración de la temperatura $\left(38,5^{\circ} \mathrm{C}\right.$ o más, fiebre persistente e hipotermia), fue más frecuente en recién nacidos con ITU, al igual que los trastornos afectivos (irritabilidad excesiva, llanto débil o llanto quejumbroso), diferencias que fueron estadísticamente significativas (tabla 2). No encontramos diferencias estadísticas significativas para temperatura al momento del ingreso, alteración de los sistemas gastrointestinal, respiratoria y cardiohemodinámica, (tabla 2).

En cuanto a los laboratorios, en neonatos con ITU se observó un número superior de leucocitos en sangre en neonatos con ITU (mediana: $13.550 / \mathrm{mm}^{3}$; RI: $10.480-17.500 / \mathrm{mm}^{3}$ vs mediana: $11.800 / \mathrm{mm}^{3}$; RI: 9.100-15.900/ $\mathrm{mm}^{3}$ ), un mayor número de neutrófilos en sangre (mediana: $8.056 / \mathrm{mm}^{3}$; RI: $5.256-10.664 /$ $\mathrm{mm}^{3}$ vs mediana: $6.384 / \mathrm{mm}^{3}$; RI: $4.520-9.350 /$ $\mathrm{mm}^{3}$ ) y proteína $\mathrm{C}$ reactiva elevada (mediana: 4,7 mg/dL; RI: 1,7-8,7 mg/dL vs mediana: 0,7 $\mathrm{mg} / \mathrm{dL}$; RI: 0,3-1,7 $\mathrm{mg} / \mathrm{dL}$ ), diferencias que fueron estadísticamente significativas (tabla 3). Para el uroanálisis, se confirmó en los neonatos con ITU un número elevado de leucocitos en orina (mediana de 35 leucocitos/campo; RI: 10-51 leucocitos/campo vs mediana de 1 leucocitos/campo; RI: 0-3 leucocitos/campo), mayor proporción de bacteriuria $(114 ; 72,2 \%$ vs $4 ; 1,2 \%)$, de nitruria positiva $(40 ; 25,6 \%$ $v s 0)$ y de estearasa leucocitaria positiva (80; $50,6 \%$ vs $4 ; 1,2 \%$ ), diferencias que fueron estadísticamente significativas (tabla 3). El Gram de orina sin centrifugar fue positivo para bacilos Gram negativos en $92(58,2 \%)$ neonatos con ITU y en ningún neonato sin ITU (tabla 3 ).

Las variables significativamente asociadas a ITU fueron sexo masculino (OR: 12,3; IC 95\%: 6,2-27), edad al momento de la fiebre 
mayor a 7 días (OR: 15,5; IC 95\%: 8,5-30,1), hospitalización neonatal previa (OR: 6; IC 95\%: 2,7-14,4), alteración de la temperatura $\left(38,5^{\circ} \mathrm{C}\right.$ o más, fiebre persistente, hipotermia), (OR: 3,5; IC 95\%: 2,2-5,6), trastornos afectivos (irritabilidad exagerada, llanto débil o llanto quejumbroso) (OR: 1,5; IC 95\%: 1-2,2), cuadro hemático alterado (OR: 3,3; IC 95\%: 1,9-5,3), proteína $C$ reactiva de $1,7 \mathrm{mg} / \mathrm{dL}$ o más (OR: 8,6; IC 95\%: 5,5-13,7), uroanálisis alterado (OR: 74,8; IC 95\%: 39,4-143,3) y Gram de orina sin centrifugar positivo para bacilo Gram negativo (tabla 4). Después del análisis multivariado, las variables que permanecieron en el modelo fueron sexo masculino, edad al momento de la fiebre mayor a 7 días, hospitalización neonatal previa, alteración de la temperatura $\left(38,5^{\circ} \mathrm{C}\right.$ o más, fiebre persisten- te, hipotermia), proteína $\mathrm{C}$ reactiva $1,7 \mathrm{mg} / \mathrm{dL}$ o más, uroanálisis alterado y Gram de orina sin centrifugar positivo para bacilo Gram negativo (tabla 4). Se observó un coeficiente de regresión logística dos o más veces mayor para uroanálisis alterado y Gram de orina sin centrifugar positivo para bacilo Gram negativo, que para las otras variables, por lo que los criterios mayores en la Escala de Predicción Diagnóstica de ITU fueron uroanálisis alterado y Gram de orina sin centrifugar positivo para bacilo Gram negativo, mientras los criterios menores fueron sexo masculino, edad al momento de la fiebre mayor a 7 días, hospitalización neonatal previa, alteración de la temperatura $\left(38,5^{\circ} \mathrm{C}\right.$ o más, fiebre persistente, hipotermia) y proteína $C$ reactiva de $1,7 \mathrm{mg} / \mathrm{dL}$ o más. La Escala Predictiva fue considerada positiva con un cri-

Tabla 1. Características maternas y neonatales en neonatos con y sin infección urinaria del tracto urinario

\begin{tabular}{|c|c|c|c|c|}
\hline Características & Medida & $\begin{array}{c}\text { ITU } \\
n=158\end{array}$ & $\begin{array}{c}\text { Sin ITU } \\
n=346\end{array}$ & $\mathbf{p}$ \\
\hline $\begin{array}{l}\text { Seguridad social en salud: } \\
\text { Sin seguridad social en salud } \\
\text { Con seguridad social en salud }\end{array}$ & $\begin{array}{l}\text { n (\%) } \\
\text { n (\%) }\end{array}$ & $\begin{array}{rr}10 & (6,4 \%) \\
148 & (93,6 \%)\end{array}$ & $\begin{array}{r}9(2,6 \%) \\
337(97,4 \%)\end{array}$ & 0,042 \\
\hline Edad materna (años) & $\begin{array}{l}\text { Promedio } \\
\text { DE }\end{array}$ & $\begin{array}{r}25,4 \\
6,5\end{array}$ & $\begin{array}{r}25,6 \\
6,8\end{array}$ & 0,867 \\
\hline Educación en años & $\begin{array}{l}\text { Promedio } \\
\text { DE }\end{array}$ & $\begin{array}{l}9,4 \\
3,9\end{array}$ & $\begin{array}{l}9,9 \\
2,6\end{array}$ & 0,338 \\
\hline Paridad & $\begin{array}{l}\text { Promedio } \\
\text { DE }\end{array}$ & $\begin{array}{l}1,8 \\
1,2\end{array}$ & $\begin{array}{l}1,8 \\
1\end{array}$ & 0,800 \\
\hline $\begin{array}{l}\text { Estrato socio-económico } \\
\qquad \begin{array}{l}1 \text { y } 2 \\
3 \text { o mayor }\end{array}\end{array}$ & $\begin{array}{l}\mathrm{n}(\%) \\
\mathrm{n}(\%)\end{array}$ & $\begin{array}{r}126(80 \%) \\
32(20 \%)\end{array}$ & $\begin{array}{r}277(80 \%) \\
69(20 \%)\end{array}$ & 0,385 \\
\hline Control prenatal con $\geq 5$ visitas & n (\%) & $104(65,8 \%)$ & $252(72,8 \%)$ & 0,109 \\
\hline ITU materna en el embarazo & $\mathrm{n}(\%)$ & $4(2,5 \%)$ & $8 \quad(2,3 \%)$ & 0,881 \\
\hline Sexo masculino & n (\%) & $148(93,7 \%)$ & $188(54,7 \%)$ & $<0,001$ \\
\hline Edad gestacional (semanas) & $\begin{array}{l}\text { Promedio } \\
\text { DE }\end{array}$ & $\begin{array}{l}39 \\
1,9\end{array}$ & $\begin{array}{l}39 \\
1,9\end{array}$ & 0,318 \\
\hline Peso al nacer (gramos) & $\begin{array}{l}\text { Promedio } \\
\text { DE }\end{array}$ & $\begin{array}{r}3.272 \\
439\end{array}$ & $\begin{array}{r}3.172 \\
525\end{array}$ & 0,981 \\
\hline Edad al momento de la fiebre (días) & $\begin{array}{l}\text { Mediana } \\
\text { RI }\end{array}$ & $\begin{array}{r}15 \\
11-23\end{array}$ & $\begin{array}{r}3 \\
2-14\end{array}$ & $<0,001$ \\
\hline $\begin{array}{l}\text { Vía de nacimiento } \\
\text { Cesárea } \\
\text { Vaginal }\end{array}$ & $\begin{array}{l}\text { n (\%) } \\
\text { n (\%) }\end{array}$ & $\begin{array}{r}52(32,9 \%) \\
106(67,1 \%)\end{array}$ & $\begin{array}{l}112(32,4 \%) \\
234(67,6 \%)\end{array}$ & 0,904 \\
\hline Hospitalización neonatal previa & $\mathrm{n}(\%)$ & $24(15,2 \%)$ & $10(2,9 \%)$ & $<0,001$ \\
\hline
\end{tabular}

ITU: Infección del tracto urinario. DE: Desviación estándar. RI: Rango intercuartil. 
Tabla 2. Características clínicas en neonatos con y sin infección urinaria del tracto urinario

\begin{tabular}{|c|c|c|c|c|}
\hline Características clínicas & Medida & $\begin{array}{l}\text { ITU } \\
\text { n: } 158\end{array}$ & $\begin{array}{l}\text { Sin ITU } \\
\mathrm{n}: 346\end{array}$ & $\mathbf{p}$ \\
\hline Temperatura al ingreso & Promedio (DE) & $37,7^{\circ} \mathrm{C}\left( \pm 0,1^{\circ} \mathrm{C}\right)$ & $37,6^{\circ} \mathrm{C}\left( \pm 0,9^{\circ} \mathrm{C}\right)$ & 0,551 \\
\hline Máxima & Mediana (RI) & $38,5^{\circ} \mathrm{C}\left(38-39^{\circ} \mathrm{C}\right)$ & $38,3^{\circ} \mathrm{C}\left(38-38,7^{\circ} \mathrm{C}\right)$ & $<0,01$ \\
\hline Persistente & n (\%) & $100(63,7 \%)$ & $78(22,7 \%)$ & $<0,001$ \\
\hline Hipotermia $\left(<36^{\circ} \mathrm{C}\right)$ & n (\%) & $10(6,5 \%)$ & $6(1,7 \%)$ & $<0,001$ \\
\hline $\begin{array}{l}\text { Alteración Gastrointestinal: Hiporexia, vomito, distensión } \\
\text { de abdomen, retorno bilioso por sonda, etc. }\end{array}$ & $\mathrm{n}(\%)$ & $42(26,6 \%)$ & $74(21,5 \%)$ & 0,200 \\
\hline $\begin{array}{l}\text { Alteración Respiratoria: Taqui o bradipnea, apnea, dificul- } \\
\text { tad respiratoria (quejido, tirajes intercostales, retracción } \\
\text { subcostal, aleteo nasal, disbalance toraco-abdominal }\end{array}$ & $n(\%)$ & $4 \quad(2,5 \%)$ & $10 \quad(2,9 \%)$ & 0,820 \\
\hline $\begin{array}{l}\text { Alteración Cardio-hemodinámica: Taqui o bradicardia, } \\
\text { mala perfusión, hipotensión }\end{array}$ & n (\%) & $12(7,6 \%)$ & $20 \quad(5,8 \%)$ & 0,438 \\
\hline $\begin{array}{l}\text { Alteración Afectiva: Irritabilidad excesiva, llanto débil, } \\
\text { Ilanto quejumbroso }\end{array}$ & n (\%) & $70(44,3 \%)$ & $120(34,8 \%)$ & 0,039 \\
\hline Ictericia que requiera fototerapia & n (\%) & $22(13,9 \%)$ & $86(24,9 \%)$ & $<0,01$ \\
\hline
\end{tabular}

ITU: Infección del tracto urinario. DE: Desviación estándar. RI: Rango intercuartil.

Tabla 3. Características clínicas y de laboratorio en neonatos con y sin infección urinaria del tracto urinario

\begin{tabular}{|llccc|}
\hline Laboratorio & Medida & ITU n: 158 & Sin ITU n: 346 & p \\
\hline $\begin{array}{l}\text { Hemograma } \\
\text { Leucocitos/mm }\end{array}$ & & & & \\
Neutrófilos/mm & & & & \\
Hemoglobina g/dL & Mediana (RI) & $13.550(10.480-17.500)$ & $11.800(91.00-15.900)$ & $<0,01$ \\
Plaquetas/mm & Mediana (RI) & $8.056(5.256-10.664)$ & $6.384(4.520-9.350)$ & $<0,01$ \\
\hline Proteína C reactiva mg/dL & Promedio (DE) & $20,3(27,6)$ & $14,4(2,6)$ & $<0,001$ \\
Uroanálisis & Mediana (RI) & $373.000(265.000-462.000)$ & $327.000(263.000-422.000)$ & 0,055 \\
Leucocitos & Mediana (RI) & $4,7(1,7-8,7)$ & $0,7(0,3-1,7)$ & $<0,001$ \\
Bacteriuria & & & & $<0,001$ \\
Nitruria & Mediana (RI) & $35(10-51)$ & $1(0-3)$ & $<0,001$ \\
Estearasa leucocitaria & $\mathrm{n}(\%)$ & $114(72,2 \%)$ & $4(1,2 \%)$ & $<0,001$ \\
Gram de orina sin centrifugar & $\mathrm{n}(\%)$ & $40(25,6 \%)$ & $4(1,2 \%)$ & $<0,001$ \\
positivo para bacilos Gram negativos & $\mathrm{n}(\%)$ & $80(50,6 \%)$ & 0 & $<0,001$ \\
\hline
\end{tabular}

ITU: Infección del tracto urinario. DE: Desviación estándar. RI: Rango intercuartil.

terio mayor o tres menores obteniéndose con ello sensibilidad 95\% (IC 95\%: 91,2-98,7\%), especificidad: 73,8\% (IC 95\%: 69,1-78,6\%) y área bajo ROC: 0,842 (IC 95\%: 0,813-0,871), con un buen ajuste del modelo (tabla 5, figuras 1 y 2). El valor predictivo positivo de la escala fue $62,5 \%$ (IC 95\%: 56,2-68,8\%), el valor predictivo negativo 97\% (IC 95\%: 94,7-99,2\%), la razón de verosimilitud positiva 3,7 (IC 95\%: $3-4,4)$ y razón de verosimilitud negativa 0,07 (IC 95\%: 0,03-0,13).

En la validación de la Escala Predictiva de
ITU, se incluyeron 108 neonatos nuevos con fiebre sin foco aparente al ingreso, de los cuales $30(27,8 \%)$ tuvieron diagnóstico de ITU y $78(72,2 \%)$ diagnóstico diferente a ITU, siendo la deshidratación hipernatrémica responsable de 66 casos $(61,1 \%)$ y la fiebre $\sin$ foco aparente de 12 casos $(11,1 \%)$. En cuanto al rendimiento de cada una de las variables encontramos: edad mayor a 7 días, sensibilidad 80\% (IC 95\%: 64-96\%) y especificidad 92,3\% (IC 95\%: 85,8-98,9\%); sexo masculino, sensibilidad 100\% (IC 95\%: 98,3-100\%) 
Tabla 4. Análisis bivariado y multivariado de factores asociados a infección del tracto urinario en neonatos

\begin{tabular}{|c|c|c|c|c|c|}
\hline Características & ORc (IC 95\%) & $\mathbf{p}$ & ORa (IC 95\%) & $\mathbf{p}$ & $\begin{array}{l}\text { Coeficiente } \\
\text { de regresión }\end{array}$ \\
\hline Sexo masculino & $12,3(6,2-27)$ & $<0,001$ & $6,7(2,3-11,9)$ & $<0,001$ & $1,9(1-2,8)$ \\
\hline Edad > 7 días & $15,5(8,5-30,1)$ & $<0,001$ & $5,2(2,3-11,9)$ & $<0,001$ & $1,6(0,8-2,4)$ \\
\hline Hospitalización neonatal previa & $6(2,7-14,4)$ & $<0,01$ & $6,1(1,9-19,4)$ & $<0,01$ & $1,8(0,7-2,9)$ \\
\hline $\begin{array}{l}\text { Alteración de la temperatura ( } \geq 38,5^{\circ} \mathrm{C} \text {, persistente, } \\
\text { hipotermia) }\end{array}$ & $3,5(2,2-5,6)$ & $<0,001$ & $2,7(1,2-5,8)$ & $<0,05$ & $0,9(0,2-1,6)$ \\
\hline $\begin{array}{l}\text { Trastorno afectivo (irritabilidad exagerada, difícil } \\
\text { de consolar, llanto quejumbroso) }\end{array}$ & $1,5(1-2,2)$ & $<0,05$ & $0,8(0,3-1,7)$ & $>0,05$ & - \\
\hline $\begin{array}{l}\text { Cuadro hemático alterado (leucocitosis y } \\
\text { neutrofilia para la edad cronológica) }\end{array}$ & $3,3(1,9-5,3)$ & $<0,001$ & $0,5(0,2-1,6)$ & $>0,05$ & - \\
\hline Proteína $C$ reactiva $\geq 1,7 \mathrm{mg} / \mathrm{dL}$ & $8,6(5,5-13,7)$ & $<0,001$ & $3,6(1,7-7,7)$ & $<0,01$ & $1,2(0,5-1,9)$ \\
\hline $\begin{array}{l}\text { Uroanálisis alterado (leucocitosis } \geq 10 / \text { campo, } \\
\text { Bacteriuria, nitruria, estearasa leucocitaria positiva) }\end{array}$ & $74,8(39,4-143,3)$ & $<0,001$ & $49,3(24,5-99,5)$ & $<0,001$ & $3,9(3,2-4,6)$ \\
\hline Gram de orina positivo & $(124,9-)$ & $<0,001$ & Predicción perfecta & $<0,001$ & - \\
\hline
\end{tabular}

ORc: Odds ratio crudo. ORa: Odds ratio ajustado.

Tabla 5. Escala de predicción diagnóstica de ITU en neonatos febriles sin foco aparente

\begin{tabular}{|c|}
\hline Criterios diagnósticos de ITU en neonatos febriles \\
\hline $\begin{array}{l}\text { Mayores: } \\
\text { 1. Uroanálisis alterado: Leucocituria } \geq 10 \text { leucocitos/campo, bacteriuria, nitruria, estearasa leucocitaria } \\
\text { 2. Gram de orina positivo para bacilos Gram negativos }\end{array}$ \\
\hline $\begin{array}{l}\text { Menores: } \\
\text { 1. Edad mayor a } 7 \text { días al momento de la fiebre } \\
\text { 2. Sexo masculino } \\
\text { 3. Hospitalización neonatal previa } \\
\text { 4. Alteración de la temperatura }\left(\geq 38,5^{\circ} \mathrm{C} \text {, persistente o } 2 \text { o más alzas térmicas } \geq 37,6^{\circ} \mathrm{C} \text { en } 24 \text { h e hipotermia o temperatura }<36^{\circ} \mathrm{C} \text { ) }\right. \\
\text { 5. Proteína } \mathrm{C} \text { reactiva elevada } \geq 1,7 \mathrm{mg} / \mathrm{dL} \mathrm{o} \geq 17 \mathrm{mg} / \mathrm{L} \text { ) }\end{array}$ \\
\hline $\begin{array}{l}\text { La escala es positiva con un criterio mayor o tres menores. } \\
\text { Rendimiento: } \\
\text { Sensibilidad: } 95 \% \text { (IC 95\%: } 91,2-98,7 \%) \\
\text { Especificidad: } 73,8 \% \text { (IC 95\%: 69,1-78,6\%) } \\
\text { Valor predictivo positivo: } 62,5 \% \text { (IC 95\%: } 56,2-68,8 \%) \\
\text { Valor predictivo negativo: } 97 \% \text { (IC } 95 \%: 94,7-99,2 \%) \\
\text { Razón de verosimilitud positiva: } 3,7 \text { (IC 95\%: } 3-4,4) \\
\text { Razón de verosimilitud negativa: } 0,07 \text { (IC 95\%: } 0,03-0,13) \\
\text { Área bajo ROC: } 0,842 \text { (IC 95\%: } 0,813-0,871)\end{array}$ \\
\hline
\end{tabular}

ITU: Infección del tracto urinario.

y especificidad 76,9\% (IC 95\%: 66,9-86,9\%); hospitalización neonatal previa fue negativa tanto en neonatos con y sin ITU; alteración de la temperatura (mayor o igual a $38,5^{\circ} \mathrm{C}$, fiebre persistente o hipotermia), sensibilidad $80 \%$ (IC 95\%: 64-96\%) y especificidad 61,5\% (IC 95\%: 50,1-73\%); proteína $\mathrm{C}$ reactiva de 1,7
mg/dL o más, sensibilidad 80\% (IC 95\%: 64$96 \%$ ) y especificidad 92,3\% (IC 95\%: $85,8-$ 98,9\%); uroanálisis alterado (leucocituria de 10 o más leucocitos por campo, con o sin bacteriuria, nitruria o estearasa positiva), sensibilidad 60\% (IC 95\%: 40,8-79,2\%) y especificidad 100\% (IC 95\%: 99,4-100\%); Gram de 

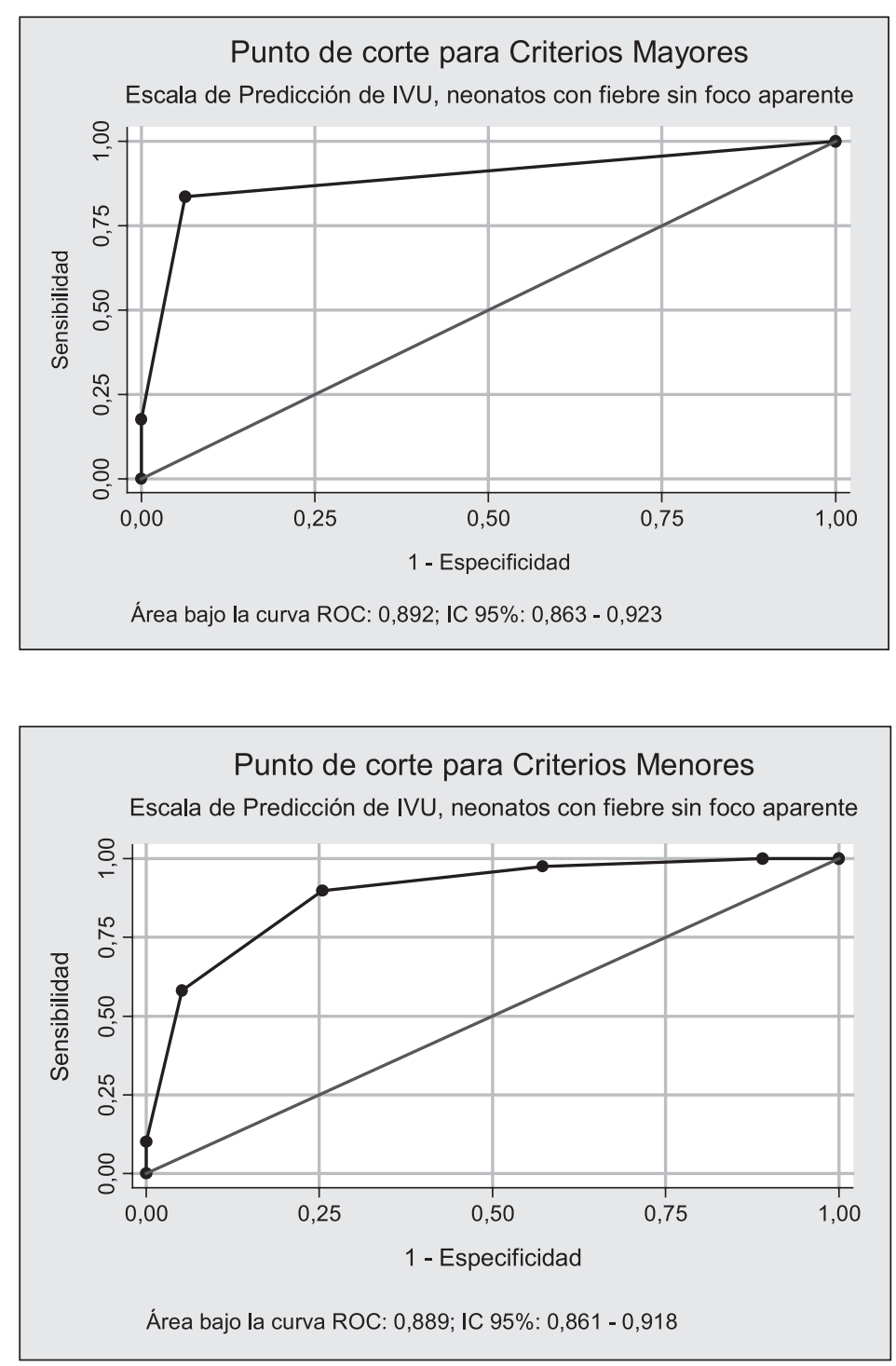

Figura 1. Área bajo la curva ROC criterios mayores en Escala de Predicción Diagnóstica de ITU, neonatos febriles sin foco aparente.

Figura 2. Área bajo la curva ROC criterios menores en Escala de Predicción Diagnóstica de ITU, neonatos febriles sin foco aparente.

orina sin centrifugar positivo para bacilo Gram negativo, sensibilidad 80\% (IC 95\%: 64-96\%) y especificidad 100\% (IC 95\%: 99,4-100\%). La Escala Predictiva de ITU positiva con un criterio mayor o tres menores presentes, tuvo una sensibilidad 100\% (IC 95\%: 98,3-100\%), especificidad 92,3\% (IC 95\%: 85,8-98,9\%), área bajo ROC 0,962 (IC 95\%: 0,932-0,991), valor predictivo positivo $83,3 \%$ (IC 95\%: $69,8-96,9 \%$ ), valor predictivo negativo $100 \%$ (IC 95\%: 99,3-100\%), razón de verosimilitud positiva 13 (IC 95\%: 6-28), no pudiendo determinar la razón de verosimilitud negativa, indicando un buen rendimiento en este nuevo grupo de neonatos febriles.

\section{Discusión}

La ITU es una enfermedad muy común en la infancia, ocurriendo en un $0,1 \%$ a $1 \%$ de todos los neonatos y en el $8 \%$ de los niños con peso al nacer menor a 1.500 gramos $^{13-16}$. Afecta 1 de cada 3 recién nacidos con infección bacteriana demostrada, y puede ser el primer indicador de anormalidades de las vías urinarias estructurales subyacentes ${ }^{17}$. La prevalencia de ITU varía 
entre $5,4 \%$ y $22,8 \%^{18}$. Las tasas de ITU varían con la edad, es baja en recién nacidos a término $(0,1-1 \%)$ y aumenta en la infancia $(9,7 \%)$. En neonatos prematuros se han observado incidencias mayores $(10 \%)$, con una relación inversa al peso al nacer ${ }^{17}$.

En nuestro trabajo confirmamos que la enfermedad afectaba más a los varones, con una relación hombre:mujer de 14,8:1. Otros autores informan que la ITU es más frecuente en varones con una relación hombre:mujer que va desde 2:1 hasta $6,6: 1$, dado el aumento de la incidencia de anomalías estructurales en los varones $^{19,20}$. Observamos que $19,7 \%$ de neonatos presentaron anomalías estructurales tipo hidronefrosis y riñón poliquístico, mientras en el 3\% se demostró pielonefritis. La alteración estructural en ecografía para López Sastre J y cols., fue superior al nuestro con $34 \%$, entre las cuales la hidronefrosis representó el 32,3\%. Confirmamos igualmente que el $23,1 \%$ de las cistouretrografías miccionales realizadas identificaron reflujo vesicoureteral, cifra similar $(23,8 \%)$ a la de López Sastre J y cols ${ }^{19}$.

Para nosotros la enfermedad ocurrió con una mediana de edad de 15 días (RI: 11-23), similar a López Sastre J y cols, para quienes la edad fue 16,86 $\pm 6,18$ días $^{19}$. La enfermedad ocurrió más frecuentemente en neonatos de término (39 $\pm 1,9$ semanas) y en neonatos de peso adecuado para la edad gestacional (3.272 $\pm 439 \mathrm{~g}$ ), datos similares a los informados por otros autores ${ }^{15,19}$. Un hallazgo interesante fue el antecedente de hospitalización neonatal previa que estuvo presente en el 15,2\% de los neonatos con ITU vs el $2,9 \%$ de los neonatos sin ITU, mostrando una fuerte asociación con ITU.

La Escherichia coli sigue siendo el patógeno principal en las ITU neonatal, tanto para nosotros como para otros autores, seguido por otras bacterias Gram negativas ${ }^{17,19-21}$. Para nosotros 26/158 (16,5\%) neonatos tuvieron aislamiento bacteriano tanto en orina como en sangre, cifra similar a la Downey LC y cols. ${ }^{24}$, quienes en 127/976 (13\%) neonatos tuvieron asilamiento bacteriano concomitante en orina y sangre.

Los signos clínicos asociados a ITU fueron alteración de la temperatura $\left(38,5^{\circ} \mathrm{C}\right.$ o más, fie- bre persistente e hipotermia) y alteración afectiva (irritabilidad excesiva, llanto débil y el quejumbroso). Estos hallazgos son similares a los descritos en otros trabajos, aunque también se han mencionado signos gastrointestinales, como la pobre alimentación ${ }^{3,17,19,21,23}$. Sin embargo, aparte de la fiebre, muchos neonatos pueden carecer de síntomas y signos que sugieran una ITU, e incluso la mitad puede tener fiebre baja o no presentarla, mientras que la mayor parte de los síntomas no son específicos del tracto urinario, como pobre alimentación, falla para crecer e ictericia prolongada ${ }^{21,23}$.

El uroanálisis y el Gram de orina sin centrifugar son los exámenes con mejor capacidad de predicción de ITU $^{23}$, describiéndose una sensibilidad de 75 a $90 \%$ y una especificidad de 70 a $82 \%{ }^{20}$. Para nosotros un número de leucocitos en orina de 10 o más por campo fue el mejor punto de corte en la predicción de ITU, sin embargo, la alteración de cualquiera de los componentes del uroanálisis y el Gram tuvo una sensibilidad de 83,5\% (IC 95\%: 77,5$89,6 \%$ ), siendo los mejores la leucocituria (77,2\%; IC 95\%: 70,4-84,1\%) y la bacteriuria (72,2\%; IC 95\%: 64,9-79,5\%). Nuestros datos concuerdan con los de otros autores, para quienes la leucocituria tiene sensibilidad $73 \%$ (IC 95\%: 32-100\%) y la bacteriuria sensibilidad 81\% (IC 95\%: 16-99\%), mientras cualquier alteración en el uroanálisis (leucocituria, bacteriuria, nitruria o estearasa leucocitaria) tiene una sensibilidad de 99,8\% (IC 95\%: 99$100 \%)^{12}$, mayor a la sensibilidad registrada en nuestro trabajo. El hemograma tiene baja sensibilidad en la predicción de ITU, mientras la proteína $\mathrm{C}$ reactiva con un valor $1,7 \mathrm{mg} / \mathrm{dL}$ o más tuvo sensibilidad de 76\% (IC 95\%: 69$82,9 \%$ ). Díaz M y cols., no hallaron asociación entre leucopenia o leucocitosis e ITU ${ }^{25}$.

$\mathrm{Ni}$ los antecedentes, ni las manifestaciones clínicas, ni el laboratorio por si solos, tienen buena capacidad predictiva en ITU neonatal, por ello, consideramos que una escala tenga un mejor rendimiento en términos de sensibilidad y especificidad. Las variables que quedaron incluidas en nuestra escala incluyeron criterios mayores, uroanálisis alterado (leucocituria de 10 o más leucocitos/campo, bacteriuria, nitruria, estearasa leucocitaria positiva) y Gram de 
orina sin centrifugar, y criterios menores, edad neonatal mayor a 7 días al momento de la fiebre, sexo masculino, antecedente de hospitalización neonatal, elevación de la temperatura de $38,5^{\circ} \mathrm{C}$ o más, fiebre persistente e hipotermia, estás últimas tres agrupadas con el nombre de alteración de la temperatura y proteína $C$ reactiva positiva con un valor de $1,7 \mathrm{mg} / \mathrm{dL}$ o más. La escala tuvo buen rendimiento predictivo, tanto en el grupo de neonatos con ITU de los cuales se obtuvo la propia escala, como en el grupo en el cual fue validada.

La infección urinaria a esta edad es un problema de extrema gravedad, con alto riesgo de sepsis, complicaciones, secuelas y muerte, por lo cual su tratamiento debe ser realizado con urgencia en un hospital. Dado la ausencia de marcadores clínicos y de laboratorio altamente sensibles que indiquen la probabilidad de una ITU en neonatos, y que los cultivos pueden tardar entre $24-48 \mathrm{~h}$ para descartar o confirmarla, destacan el importante papel que puede desempeñar esta escala como medio fiable para sospechar e identificar esta patología, ya que esto nos permitiría de una manera más objetiva y oportuna el inicio de los antibióticos.

\section{Referencias}

1.- Smitherman H, Macias C: Evaluation and Management of Fever in the Neonate and Young Infant (Less than three months of age). (publicación en línea). 2012 ago. (citada 21 de agosto de 2012: 20 pantallas). Disponible en: http://www.uptodate.com/contents/evaluation-andmanagement-of-fever-in-the-neonate-and-young-infantless-than-three-months-of-age\#H2.

2.- Fernández RC, Trenchs-Sainz V, Curcio BA: Asistencia a neonatos en el servicio de urgencias de un hospital pediátrico terciario. An Pediatric (Barc) 2006; 65 (2): 123-8.

3.- Mendoza LA, Arias MD: Revista de Enfermedades Infecciosas en Pediatría 2009; 22 (88): 105-13.

4.- Zorc J, Kiddoo A, Shaw MD: Diagnosis and management of pediatric urinary tract infections. Clin Microbiol Rev 2005; 18: 417-22.

5.- Larcombe J: Urinary tract infection in children. Clin Evid 2005; 14: 1-12.

6.- Zorc J, Levine D, Platt S, et al: Clinical and demographic factors associated with urinary tract infections in young febrile infants. Pediatrics 2005; 116: 644-8.

7.- Littlewood JM, Kite P, Kite BA: Incidence of Neonatal Urinary Tract Infection. Arch Dis Childh 1969; 44: $617-$ 20.

8.- Meter D: Infection in the newborn. Roberton's. Textbook of Neonatology. Forth Edition. Ed. Janet M Rennie 2005: 993-1092.

9.- World Health Organization, Department of Child and Adolescent Health and Development. Urinary Tract Infections in Infants and Children in Developing Countries in the Context of IMCI, Discussion papers on child health 2005; 1-24.

10.- Ventura MP, Samper MP: Infección Urinaria en el Recién Nacido. [Monografía en internet]. Zaragoza: Asociación Española de Pediatría 2008. Disponible en: http//www.aeped.es/protocolos/.

11.- Pennesi $M$, Travan L, Peratoner L, et al: Is antibiotic prophylaxis in children with vesicoureteral reflux effective in preventing pyelonephritis and renal scars? A randomized, controlled trial. Pediatrics 2008; 121 (6): e1489-94.

12.- American Academy of Pediatrics. Committee on Quality Improvement. Subcommittee on Urinary Tract Infection. The diagnosis, treatment, and evaluation of the initial urinary tract infection in febrile infants and young children. Pediatrics 1999; 103: 843-52.

13.- Nowell L, Moran C, Smith B, et al: Prevalence of Renal Anomalies Following Urinary Tract Infections in Hospitalized Infants Less Than Two Months of Age. J Perinatol 2010; 30 (4): 281-5.

14.- Edelmann CM Jr, Ogwo JE, Fine BP, Martínez AB: The prevalence of bacteriuria in full-term and premature newborn infants. J Pediatr 1973; 82: 125-32.

15.- Gerard M, Diakite B, Bedu A, et al: Urinary tract infection in the newborn infant. Arch Pediatr 1998; 5 (Suppl 3): 254S-9S.

16.- Maherzi M, Guignard JP, Torrado A: Urinary tract infection in high-risk newborn infants. Pediatrics 1978; 62: 521-3.

17.- Barton M, Bell Y, Thame M, Nicholson A, Trotman H: Infección de las Vías Urinarias en Neonatos Ingresados con Serias Infecciones Bacterianas en el Hospital Universitario de West Indies. West Indian Med J 2008; 57 (2): 101-5.

18.- Álvarez RA, Ortiz SO, Hernández N: Validación de nuevos parámetros predictivos de infecciones bacterianas severas en niños febriles menores de 36 meses. Rev Cubana Pediatr 1999; 71 (4): 197-204.

19.- López Sastre J, Ramos A, Gil C, Fernández B, Crespo $M$ : Urinary tract infection in the newborn: clinical and 
radio imaging studies. Pediatr Nephrol 2007; 22: 1735 41.

20.- Segura E, Calderón E, Mancilla J, Sánchez G, Solórzano F: Consenso Mexicano en Infecciones de Vías Urinarias en Pediatría. Acta Pediatr Mex 2007; 28 (6): 289-93.

21.- Fernández M, Solís G, Málaga S, et al: Comparación temporal y bacteriológica de la infección urinaria neonatal. An Pediatr (Barc). 2008; 69 (6): 526-32.

22.- Cícero M, Rodrigues $S, D^{\prime}$ Andrea $R$, Berardi $R$, Ono $N$, Costa F: Urinary tract infection in full-term newborn infants: Value of urine cultura by bag specimen collection. Rev Hosp Clín Fac Med S Paulo 1999; 54
(3): 91-6.

23.- Cataldi L, Zaffanello M, Gnarra M, Fanos V: Neonatal Nephrology Study Group of the Italian Society of Neonatology. Urinary tract infection in the newborn and the infant: state of the art. J Maternal-Fetal and Neonatal Medicine, 2010; 23 (S3): 90-3.

24.- Downey LC, Benjamin DK Jr, Clark RH, et al: Urinary tract infection concordance with positive blood and cerebrospinal fluid cultures in the neonatal intensive care unit. J Perinatol 2013; 33: 302-6.

25.- Díaz M, Ahmed Y, Martínez H: Evaluación del recién nacido febril y predicción de infección del tracto urinario. Rev Cubana Pediatr 1998; 70 (4): 170-5. 